\title{
O IDEÁRIO REPUBLICANO E A CONSOLIDACCAO DA ESCOLA NORMAL EMS SANTA CATARINA
}

\author{
THE REPUBLICAN IDEOLOGY AND THE CONSOLIDATION OF \\ THE NORMAL SCHOOL IN SANTA CATARINA \\ EL IDEARIO REPUBLICANO Y LA CONSOLIDACIÓN DE LA ESCUELA \\ NORMAL EN SANTA CATARINA
}

Ana Paola Sganderla*

https://orcid.org/oooo-0oo3-4602-9717

Diana Carvalho de Carvalho**

(iD) https://orcid.org/oooo-ooo2-6924-2214

\begin{abstract}
REVISTA PEDAGÓGICA
Revista do Programa de Pós-graduação em Educação da Unochapecó | ISSN 1984-1566 Universidade Comunitária da Região de Chapecó | Chapecó-SC, Brasil Como referenciar este artigo: SGANDERLA, A. P.; CARVALHO, D. C. O ideário republicano e a consolidação da escola normal em Santa Catarina. Revista Pedagógica, Chapecó, v. 22, p. 1-20, 2020. DOI: https://doi.org/10.22196/rp.v22io.4471
\end{abstract}

\begin{abstract}
RESUMO: Este artigo tem como foco as aspirações de ordem e conformação na formação de professores nos anos finais da monarquia e no início da República, a partir da análise de discursos dos governadores do Estado de Santa Catarina e na legislação educacional referente à Escola Normal. As iniciativas para a instituição da Escola Normal são anteriores à República, onde já observam o direcionamento das questões morais, da adequação de comportamentos e dos cuidados de saúde e higiene, bem como a preocupação com a causa educacional para formação do povo catarinense, mesmo com as descontinuidades que teve o curso de formação. No regime republicano, por sua vez, foram centrais a ideias de mudança de hábitos da população, principalmente, sobre a formação de uma nova mentalidade dos professores que poderiam ser os agentes responsáveis pela conformação da população às questões morais que os dirigentes consideravam necessárias à República.
\end{abstract}

Palavras-chave: República. Escola Normal. Formação de Professores.

ABSTRACT: This article will focus on the aspirations of order and conformation present in the formation of professors in the final years of the monarchy and in the beginning of the Republic as can be seen by the analysis in discourses of the governors of the State of Santa Catarina and in the educational legislation referring to the Normal School. The initiatives for the institution of the Normal School are prior to the Republic where they already observe the orientation of moral issues, the adequacy of behaviors and health care and hygiene, as well as the concern with the educational cause for the formation with the discontinuities that took place in the form of teachers. In the republican regime, in turn, they were central to ideas of change of habits of the population and mainly on the formation of a new mentality of the teachers that could be the agents responsible for the formation of the population the moral questions that the leaders considered necessary to the Republic.

Keywords: Republic. Normal School. Teacher Formation.

RESUMEN: El presente artículo tendrá como foco las aspiraciones de orden y conformación presentes en la formación de profesores en los años finales de la monarquía y en el inicio de la República como se puede constatar por el análisis en discursos de los gobernadores del Estado de Santa Catarina y en la legislación educativa referente a la Escuela Normal. Las iniciativas para la institución de la Escuela Normal son anteriores a la República donde ya observan el direccionamiento de las cuestiones morales, de la adecuación de comportamientos y de la atención de salud e higiene, así como la preocupación por la causa educativa para la formación del pueblo catarinense mismo con las discontinuidades que tuvo el curso de formación. En el régimen republicano, a su vez, fueron centrales a ideas de cambio de hábitos de la población y principalmente sobre la formación de una nueva mentalidad de los profesores que podrían ser los agentes responsables de la conformación de la población las cuestiones morales que los dirigentes consideraban necesaria a la República.

Palabras claves: República. Escuela normal. Formación de profesores. 


\section{Introdução}

A proclamação da República, em 15 de novembro de 1889, trouxe aspirações das mais diversas quanto ao novo Brasil que se visava construir. Monarcha (1999, p. 167-168) sintetiza as mudanças no cenário da época:

[...] a Monarquia se despede do trabalho escravo; a República despede o poder moderador, a vitalicidade do Senado, a eleição a base de renda, a centralização política, a escolha dos presidentes provinciais e a nobreza intitulada. Proclama-se a República democrático-liberal, a participação do povo na vida pública, o trabalho livre e assalariado, a eleição para os cargos públicos a descentralização político-administrativa - o federalismo - o strugle of life e a alvenaria de tijolo.

Na primeira metade da República Velha (1889-1914), quem assumiu um papel preponderante na definição dos destinos da educação foram as oligarquias estaduais, que tinham sua base no campo e para as quais a instrução não era sentida como uma necessidade. A educação do povo foi objeto de mobilização apenas nos grandes centros urbanos, por conta do processo crescente de industrialização. De acordo com Paiva (2003, p. 89), "O sistema de dominação política consubstanciado na política dos governadores, nas fraudes eleitorais, no sistema de reconhecimento dos eleitos, no próprio federalismo que possibilitava a preservação do domínio estadual das oligarquias rurais - em nada favorecia a difusão do ensino popular".

A educação era pensada, nesses centros urbanos, como condição para o bom funcionamento das instituições republicanas. Os republicanos, imbuídos das ideias positivistas, organizaram primeiramente a Escola Normal e o ensino primário, que seriam, na sua compreensão, "um centro multiplicador das luzes, que colocam as idéias [sic] em marcha, impulsionando a história em direção ao progresso e à liberdade" (MONARCHA, 1999, p. 172).

A substituição do saber fragmentado se tornou essencial para os educadores republicanos. Assim, a ordenação do conhecimento em uma perspectiva de síntese científica seria imprescindível e o programa enciclopédico traria a viabilidade de instituir um conjunto de conhecimento a ser ensinado a todos, em que estava em pauta não apenas a modificação dos conhecimentos, mas dos costumes sociais e das condutas morais, culminando com a reforma social (MONARCHA, 1999).

Assim, a Educação se configurou como um espaço privilegiado para construção e regeneração, caso fosse necessário, dos cidadãos republicanos em homens civilizados
* Doutora em Educação pela Universidade Federal de Santa Catarina. Professora colaboradora no Departamento de Educação da Universidade Estadual de Ponta Grossa e no Departamento de Psicologia da Universidade Estadual do Centro Oeste, Paraná.

E-mail: anapaolas@gmail.com

** Doutora em Educação: História, Política e Sociedade pela Pontifícia Universidade Católica de São Paulo e pós-doutorado em Educação pela Universidade Federal de São Paulo. Professora titular da Universidade Federal de Santa Catarina.

E-mail: dianacc@terra.com.br 
e ordeiros, com o fim de conformar toda uma gama de indivíduos:

\begin{abstract}
A regeneração da nação e a moralização das massas resultariam dessa forma, de uma educação voltada para o trabalho e para a vida pública. Essa tarefa fazia a função da escola avançar os limites restritos à transmissão de conhecimento, para alcançar um tipo de formação que pretendia atingir a totalidade do indivíduo (CAMPOS, 2008, p. 208).
\end{abstract}

A ideia de, pela escola, se formar um novo homem, ciente de seu espaço nas teias sociais, está diretamente ligada aos preceitos da Modernidade, já difundidos na Europa desde o século XVII: o indivíduo passa a ser o centro da sociedade, as ideias metafísicas são depostas em favor das concepções da ciência e a igreja não é mais central no domínio do homem, que, agora, tem no Estado seu conformador. Segundo Cambi (1999, p. 278), o que se instituiu como modernidade foram os processos de reviravolta na sociedade ocidental que mudaram sua identidade: "como o Estado moderno, a nova ciência, a economia capitalista; e ainda: a secularização, a institucionalização da sociedade, a cultura laica e a civilização de boas maneiras”.

Nesse cenário de amplas mudanças sociais, o sujeito se modifica, assim como sua relação com a sociedade: "O sujeito moderno é realmente um "si" individual e consciente da própria irrepetibilidade, mas é também um sujeito radicalmente governado pela sociedade e pelas suas regras, já que cada vez menos pode viver sem ela, ou longe dela" (CAMBI, 1999, p. 279). O homem da modernidade seria o homem polido. Para ensinar esse sujeito, muitos manuais sobre civilidade foram escritos nos séculos seguintes, repletos de conselhos, orientações, regras, modelos a serem copiados pelo homem moderno, que precisava, antes de tudo, aprender a ser civilizado (BOTO, 2002; BASTOS, 2008).

No presente artigo, focalizaremos as aspirações de ordem e conformação da nova mentalidade dos professores, que se fizeram presentes tanto nos discursos dos governadores do Estado de Santa Catarina quanto na legislação educacional referente à Escola Normal.

Cabe destacar que as iniciativas para a instituição da Escola Normal ${ }^{1}$ em Santa Catarina são anteriores à República, e nelas já se observam o direcionamento das questões morais, da adequação de comportamentos e dos cuidados de saúde e higiene, como também a preocupação com a causa educacional para formação do povo catarinense. Dessa maneira, a primeira parte deste texto trata, justamente, das primeiras iniciativas de instalação de uma Escola Normal no estado, onde evidenciamos as

\footnotetext{
1 De acordo com Maria Isabel Giner (1985 apud SCHAFFRATH, 2008, p. 147), a nomenclatura Escola Normal tem sua história ligada ao ensino francês, a partir de Frederico II da Prússia (Alemanha) que depois da Guerra dos Sete Anos (conflito entre grandes monarquias européias como França e Inglaterra no século XVIII) decidiu compor um novo sistema educacional onde o ensino fosse obrigatório e houvesse "normas" para a formação de professores. Foi então que os seminários franceses destinados à formação docente foram designados com o nome de "Escolas Normais".
} 
descontinuidades desse processo. A consolidação da Escola Normal no regime republicano é tema na segunda parte.

\section{Primeiras iniciativas de implantação do ensino normal em Santa Catarina}

A educação e a formação de professores são temas que invadem a cena política catarinense nos anos de 1870, parecendo, às elites catarinenses, o caminho correto a ser seguido para a formação moral do cidadão de Santa Catarina. Essa ideia é expressa no discurso do Presidente da Província, Doutor João Capistrano Bandeira de Mello Filho², sobre a instrução pública catarinense, em março do ano de 1876, na Assembleia Legislativa:

Entre todos os assuntos que podem merecer a atenção de uma sociedade, o mais elevado seria a instrução pública, pois somente ela seria capaz de dar ao cidadão a consciência de seus deveres, imprimir em seus atos o selo de sua dignidade, torná-lo incompatível com o crime, e fazê-lo apto para os diversos misteres da vida pública. (MELLO FILHO, 1876, p. 40).

Para o Presidente da Província, seguindo o exemplo norte-americano ${ }^{3}$, investindo-se em instrução pública seriam minimizados os gastos com guerras e as despesas com polícia e se formaria uma mocidade designada por ele como futuro da Pátria, bem como se disporiam as bases para o progresso. Ele reconhece que a instrução pública catarinense, no ano de 1876, carecia de uma Escola Normal, considerando que o ensino do estado, à época, contava com 137 escolas públicas e particulares, com um total de 4.227 alunos.

Mello Filho (1876) identifica, ainda, a falta de uma Escola Normal para formação dos professores como a causa da lentidão do desenvolvimento do ensino primário público catarinense, que, não possuindo educadores, não teria como elevar-se e regenerar-se. Em sua opinião, de nada adiantariam os edifícios escolares, as mobílias, os métodos e livros, se não houvesse professores bem formados. Assim, ele define o papel da Escola Normal:

[...] No meu sentir, é incontestável que da Escola Normal depende a elevação ou antes a regeneração da instrução primária na província. Não serão bastantes, se os tivéssemos, esplêndidos edifícios, mobílias de luxo, métodos e compêndios excelentes.

O essencial são os professores, e estes só as escolas normais podem fazer e educar [...]. (MELLO FILHO, 1876, p. 41).
2 Lente catedrático da Faculdade de Direito do Recife. Foi também presidente das Províncias do Rio Grande do Norte, Maranhão, Pará e Bahia.

\begin{abstract}
3 Fiori (1991) chama a atenção para o fato de que, até a República, a inspiração dos governantes para a busca de soluções para os problemas educacionais em Santa Catarina tinha como fonte as sistemáticas adotadas nos países mais adiantados do mundo, especialmente, os países da Europa. Com o advento da República, os governantes passaram a mirar-se em modelos nacionais, em particular, os paulistas, que tiveram a influência de educadores norte-americanos.
\end{abstract}


O Presidente da província catarinense faz referência, em seu discurso, ao Ministro da Educação e historiador francês François Guizot ${ }^{4}$, responsável por uma reforma considerável da instrução pública francesa, em 1833, em que foram valorizadas questões como vigilância dos conteúdos e dos valores a serem ensinados, e uma educação diferenciada pelas classes sociais, a fim de se garantir o status já definido e impedir as manifestações populares contra o regime. Das ideias de Guizot, o Presidente reproduz aquelas que reforçam o papel do professor e as qualidades importantes esse profissional a ser formado pela Escola Normal e que tem no magistério seu sacerdócio:

Quanto vale o mestre, tanto vale a escola.

E que feliz conjunto de qualidade são precisas para fazer um bom mestre?

Um bom mestre é um homem que deve saber muito, mais do que ensina, para ensinar com inteligência e gosto; deve viver em espera humilde, e, entretanto, ter a alma elevada para conservar a dignidade dos sentimentos, sem o que nunca alcançará o respeito e a confiança das famílias; deve possuir a rara aliança da brandura a firmeza, não ignorando seus direitos, porém pensando muito mais nos seus deveres; sobretudo não procurando sair de sua profissão, porque nesta faz o bem; "decidido a viver e morrer no meio da escola, para ele é serviço a Deus e a pátria" com as escolas normais tudo se consegue, e o ensino regenera-se, porque o mestre está habilitado para o desempenho de sua função (MELLO FILHO, 1876, p. 42).

Convencido do valor das Escolas Normais e de seu papel para o ensino primário público catarinense, João Capistrano Bandeira de Mello Filho (1876, p. 42) recomenda a criação de uma escola para a formação de professores em Santa Catarina, a quem elege como "[...] medida salvadora da instrução primária, atualmente de resultados medíocres na situação em que vemos”. Como forma de efetivar tal criação, alguns professores do Ateneu Provincial seriam aproveitados, recebendo aumento de salário. O Presidente ainda salienta a necessidade urgente de regulamentação e reorganização da instrução pública catarinense.

Fica evidente nas palavras do Presidente provincial seu posicionamento favorável à criação de uma instituição destinada à formação de professores primários em Santa Catarina, modificando a forma com que tradicionalmente havia sido tratada essa questão: culpabilizando as famílias, os professores ou ambos pelos fracassos da instrução primária.
4 Para um aprofundamento das ideias de Guizot sobre educação consultar "Guizot e a Educação. História da Educação”, de Jussemar Weiss (2001). 
Luciano $(2001)^{5}$, ao analisar o surgimento e expansão do magistério público catarinense no século XIX, entre os anos de 1836 e 1889 , destaca que era recorrente no discurso dos governantes daquele período a crítica aos pais pela indiferença frente à educação dos filhos, considerando-se o número pequeno de alunos em algumas escolas, bem como aos professores das escolas públicas por sua atuação, responsabilizando-os pelos problemas enfrentados:

Ao final de 1859, o governo continuava responsabilizando os pais (por não encaminharem seus filhos às escolas) e os professores (por não remeterem o quadro estatístico com a freqüência [sic] dos alunos) pela situação da instrução, eximindo-se da responsabilidade, sob a justificativa de que havia escolas e docentes suficientes. Era como se esses elementos fossem capazes de garantir a freqüência [sic] escolar e o desenvolvimento do ensino público (LUCIANO, 2001, p. 25).

É nesse contexto que, em abril de 1876 , é criada a primeira Escola Normal em Santa Catarina, segundo a Lei $\mathrm{n}^{\circ} 807$, de 20 abril de 1876, que "Cria uma Escola Normal, que funcionará no edifício do Ateneu Provincial” (PROVÍNCIA DE SANTA CATARINA, 1876, p. 81). A criação de uma instituição específica para a formação docente foi motivada, segundo o discurso oficial, pelo aumento, especialmente, do número de escolas e alunos após a obrigatoriedade do ensino primário (1874) e pela falta de professores, pois muitos ainda reprovavam nos exames de admissão realizados pela Província catarinense.

Na lei de criação da Escola Normal, o Presidente afirma que confia aos professores do Ateneu Provincial o ensino de matérias dessa escola, bem como indica que haverá um incremento nos seus salários: "Art. $2^{\circ} \mathrm{O}$ Presidente da Província encarregará do ensino das matérias, próprias de uma escola normal, aos lentes do Ateneu Provincial, que julgar necessários, concedendo-lhes por esse trabalho a gratificação anual de 400\$rs" (PROVINCIA DE SANTA CATARINA, 1876, p. 81).

Na tentativa de atribuir maior importância à Escola Normal criada junto ao Ateneu Provincial, estabeleceu-se que somente os candidatos do sexo masculino que tivessem sido aprovados nas matérias do curso normal, ou aqueles com nível superior, ou, ainda, os religiosos, podiam prestar exames para admissão como professores nas escolas de primeiras letras:

Art. 3. Concluído o estadio da escola, na forma do seu regulamento, só serão admitidos a prestar exame para preenchimento das
5 A tese de Fábia Liliã Luciano (2001) se dedicou ao estudo da gênese e da expansão do magistério público catarinense no século XIX, entre os anos de 1836 a 1889 , buscando compreender os interesses políticos e ideológicos que permeavam a província, suas relações e contradições. A autora reconstitui o cenário da época com base em relatórios, discursos e mensagens dos Presidentes da Província catarinense, relatórios dos Diretores da Instrução Pública, atas das Câmaras de Vereadores e correspondências dos Diretores da Instrução Pública, além de analisar Leis, Decretos, Resoluções, Regimentos e Regulamentos direcionados à instrução e ao magistério público. $\mathrm{O}$ ano de 1836 é considerado como marco para a regulamentação do magistério catarinense e os resultados encontrados pela autora permitem compreender o pano de fundo em que foram engendradas as necessidades de criação da Escola Normal. 
escolas de primeiras letras do sexo masculino, os alunos dela, que tiverem sido aprovados em todas as matérias do curso, exceto clérigos de ordens sacras, os doutores, os bacharéis, e aqueles que exibirem provas de terem sido aprovados em exames nos cursos superiores. (PROVÍNCIA DE SANTA CATARINA, 1876, p. 81).

Em 1880, foi realizada nova reformulação da instrução pública catarinense pela Lei $\mathrm{n}^{\circ} 898$, que organiza a educação catarinense em três categorias de escolas: $1^{\circ}, 2^{\circ}$ e $3^{\circ}$ entrância, dependendo de onde se localizavam (PROVÍNCIA SANTA CATARINA, 1880). Essa nova organização da instrução tornou periódico os concursos para o magistério na Província, de acordo com a categoria de escola:

Anualmente serão postas em concurso as escolas de $1^{\circ}$ entrância, que compreendem as das freguesias, arraiais e outras povoações; de seis em seis meses as de $2^{\circ}$ entrância, que compreendem as das cidades e vilas, de três em três meses as de $3^{\circ}$ entrância, que compreendem as da capital (PROVÍNCIA SANTA CATARINA, 1880, p. 63).

O ensino secundário e normal continuou sob a responsabilidade do Ateneu Provincial, mas foram acrescidas as cadeiras de Português, Pedagogia e Metodologia para os professores que já atuavam na educação pública ou para aqueles que pretendessem preparar-se para a profissão. Além das cadeiras supracitadas, a formação também incluía as matérias de Francês, História e Geografia Elementar (PROVÍNCIA DE SANTA CATARINA, 1880).

A frequência e a formação no Curso Normal do Ateneu Provincial davam direito à promoção na carreira do magistério, bem como afastamento remunerado para formação, embora esse benefício fosse ofertado a poucos professores do ensino primário catarinense. Essa situação indica a importância que o Curso Normal começa a adquirir para formação, ingresso e remuneração no magistério público, o que pode ser constatado no trecho a seguir:

Inciso $2^{\circ} \mathrm{O}$ presidente da província poderá conceder anualmente permissão a cinco professores de instrução primária, quando muito, para estudarem as matérias que constituem o curso normal, vencendo ordenado. Inciso $5^{\circ} \mathrm{O}$ professor que tiver curso normal terá direito à remoção para escola de categoria superior àquela em que se achar, entrando imediatamente no gozo das vantagens de tais escolas, quando não haja vaga (PROVÍNCIA DE SANTA CATARINA, 1880, p. 64). 
Outro indício do valor atribuído à Escola Normal é o fato de que, para ascenderem dentro das diferentes categorias de escola, os professores deveriam prestar exame, exceto se fossem graduados ou tivessem sido aprovados em uma Escola Normal do Brasil:

No caso de pretender um professor ser removido para escola de categoria superior àquela em que estiver, deverá prestar exame prévio das matérias que não estiverem compreendidas na categoria em que se achar, salvo se for graduado em qualquer das academias ou cursos superiores do império, ou provar que foi plenamente aprovado em qualquer escola normal. (PROVÍNCIA DE SANTA CATARINA, 1880, p. 63).

Apesar dos esforços para oferecer um Curso Normal junto ao Ateneu, a Lei $\mathrm{n}^{\circ} 898$, de 1880 , não vigorou e, em 1882, foi expedido novo ato provincial que aprovou instruções provisórias. No entanto, o Curso não chegou a ser instalado por falta de alunos candidatos às vagas disponibilizadas. Uma das causas da pouca frequência e das poucas matrículas nas escolas primárias e no Curso Normal era a precária infraestrutura da cidade de Desterro ${ }^{6}$ em 1880 , como, por exemplo, a falta de estradas e a dificuldade de se locomover do interior da Ilha para a cidade?

Com a escassez de alunos, o Ateneu fechou no ano de 1883 e deu lugar à criação do Instituto Literário e Normal, composto por ensino primário, secundário e Escola Normal. Em execução a Lei ${ }^{\circ}$ 1029, de 29 de maio de 1883 , o Presidente da Província, Theodoro Carlos de Farias Souto, expediu um regulamento, efetivando, assim, as mudanças: "Art.1: O atual Ateneu Provincial receberá o nome de Instituto Literário e Normal e terá por fim distribuir o ensino primário, secundário e normal” (PROVÍNCIA DE SANTA CATARINA, 1883, p. 749).

O regulamento definia que o Curso Normal teria a duração de dois anos e se destinava à formação de professores primários, de ambos os sexos:

Art.12. Sob a direção imediata do Reitor do Instituto, haverá no mesmo estabelecimento uma escola normal destinada a formar professores para o ensino primário.

Art.13. A escola normal será mista. (PROVÍNCIA DE SANTA CATARINA, 1883, p. 751).

Embora neste regulamento, diferente do que foi proposto em 1876 , fosse facultado o ingresso das mulheres no curso, elas deveriam permanecer em local diferente dos homens, conforme dispõe o Artigo 18 do regulamento: "As
6 Nossa Senhora do Desterro foi elevada à categoria de Vila em 1736. No ano de 1738 foi nomeada sede da Capitania de Santa Catarina. Essa denominação da capital da província se manteve até 1894, quando recebeu o nome de Florianópolis em homenagem a Floriano Peixoto, então Presidente da República. Graças à posição estratégica da Ilha de Santa Catarina para a defesa da colônia, sua ocupação foi feita com fins militares, para produção de alimentos às tropas do governo e fornecer soldados, o que pode explicar sua estagnação econômica até os primeiros 50 anos da Independência. O estabelecimento dos açorianos na Ilha de Santa Catarina a partir de 1748 deflagrou o processo de constituição do espaço urbano com a incrementação de serviços. A elite desterrense constituiu-se, inicialmente, por pequenos proprietários, funcionários civis e militares, comerciantes, armadores e construtores de navios (SCHAFFRATH, 1999).

7 Schaffrath (1999, p. 57) faz uma descrição das condições de urbanização de Desterro nos anos de 1880: "[...] ruas estreitas, sujas e sem calçamento; abastecimento de água precário pelas condições de higiene e distribuição; a falta de higiene tornava as ruas e praias focos de doenças infecciosas; dificuldades na iluminação noturna, que era realizada com óleo de baleia”. 
senhoras que frequentarem o curso terão lugar distinto, sendo permitido a seus pais, maridos, irmãos ou protetores acompanhá-las durante as lições" (PROVÍNCIA DE SANTA CATARINA, 1883, p. 752).

Para terem matrícula admitida, os candidatos à Escola Normal deveriam provar idade, moralidade, saúde, ter autorização para estudar, caso fossem menores de idade e lograr aprovação em exames orais e escritos nas matérias de instrução moral e religiosa, leitura, escrita, operações fundamentais de aritmética e princípios de gramática (PROVÍNCIA DE SANTA CATARINA, 1883).

Como é possível observar no regulamento de 1883 , questões morais e de saúde poderiam impedir o acesso à Escola Normal e regular a presença das mulheres, as quais poderiam ser acompanhadas por homens durante seu período de estudo. Tais questões estão longe de serem abolidas da educação catarinense e mantêm-se presentes, mesmo que formuladas de maneira distinta, até os anos de 1920.

As primeiras nomeações de professores para as cadeiras criadas ou restauradas no Instituto Literário e Normal cabiam ao Presidente da Província, sem concurso. No entanto, as nomeações a seguir deveriam ser providas via concurso. Para ser escolhido como professor(a) do Instituto, os aspectos morais e de formação apareciam como prerrogativa no Inciso Único: "As primeiras nomeações livres recairão sobre pessoas de reconhecida idoneidade, gozando de notoriedade, dentro e fora da Província, nas ciências ou nas letras ou no magistério" (PROVÍNCIA DE SANTA CATARINA, 1883, p. 750).

O Curso Normal instalado em Santa Catarina, em 1883, porém, não atingiu o esperado quanto ao número de matrículas nos anos seguintes a sua implantação. Entre as dificuldades enfrentadas, destacavam-se a falta de recursos para o pagamento das taxas, a distância da escola, os baixos salários dos professores e o apadrinhamento político para preenchimento de cargos públicos, entre eles, a nomeação dos professores (SCHAFFRATH, 1999).

Na verdade, o cenário de transição do Império para a República é o de ausência de incentivos e políticas da Província dirigidas à Educação, em geral, e à formação docente, em particular:

Às vésperas da proclamação da República, o ensino elementar apontava estatísticas inferiores às décadas passadas, principalmente pela redução de alunos e professores. A falta de docentes pode ser pensada à luz da ausência de uma política de carreira, levando-o ao abandono da função em busca de outras atividades, ou mesmo preferindo a docência em escolas particulares. Apesar do expressivo 
movimento no ensino catarinense promovido, principalmente, pelo aumento de escolas entre os anos de 1870 e início dos anos 1880, a instrução e o magistério padeceram de dificuldades, ligadas às condições físicas, pedagógicas, administrativas, (carência de um plano de carreira que pudesse valorizar a profissão). Essa situação permeou o período imperial e adentrou o republicano devido à falta de investimentos e recursos para implementação de uma política para o magistério público. (LUCIANO, 2001, p. 37).

\section{A escola normal na Santa Catarina republicana}

A primeira reforma republicana na instrução catarinense ocorreu pelo Decreto $\mathrm{n}^{\circ} 155$, de 10 junho de 1892. Nessa reforma, as questões de instrução da mocidade para a melhor adaptação ao social são tratadas como necessidades urgentes, conforme indicam as palavras do governador interino Manoel Joaquim Machado ${ }^{8}$ :

De todos os problemas, aquele que por sua magnitude e por sua importância mais preocupa aos que se dedicação ao engrandecimento da Pátria é indubitavelmente o da instrução da mocidade, que cada dia vemos surgir em todos os lugares mais complexos, e exigindo constantemente nova solução, que melhor se adapte às condições de existência e as transformações do organismo social. É dever de elevado patriotismo ter-se como interesse supremo, objeto de todos os esforços, a cultura intelectual daqueles a quem está reservado o futuro (SANTA CATARINA, 1892, p. 218).

O Governador atribui papel central à instrução pública em seu mandato, já que se encontrava sem cuidados e muito se tinha por fazer em termos de formação de professores e organização das escolas para que funcionassem com regularidade:

Não foram precisos muitos dias para conhecer que neste Estado, a instrução pública estava completamente descurada, e que tudo estava por fazer-se.

As ligeiras informações que obtive ofereceram-me logo dados para saber que não existira um corpo de professores com as habilitações precisas, e nem as escolas eram dotadas com os meios indispensáveis a seu regular funcionamento. (SANTA CATARINA, 1892, p. 219).
8 Santa Catarina, no início da República, teve como governador interino o tenente Manoel Joaquim Machado, que foi enviado do Rio de Janeiro como interventor estadual pelo então presidente Floriano Peixoto. O estado estava sob o domínio político dos federalistas, que apoiavam o governo central e venceram as eleições para o congresso estadual; os republicanos nem participaram desse processo, pois não tinham o apoio do governador ao seu projeto político. De acordo com Neckel (2003), as disputas que ocorriam no Estado diziam respeito muito mais à definição do controle político pelas elites catarinenses que disputavam o poder do que aos aspectos ideológicos relacionados ao novo regime. 
No entender do Governador, as reclamações da sociedade eram fruto de partidarismo, e não de verdadeiro amor ao ensino, o que gerava uma mocidade imersa na ignorância e que deveria ser salva o quanto antes:

De todos os lados recebia reclamações quase sempre oriundas de paixões partidárias e raramente filhas do amor ao ensino.

Conheci desde logo que me achava diante de um caos, e que era necessário quanto antes salvar a mocidade catarinense do abismo da ignorância para onde a encaminharam sem nenhum amor a seu futuro. (SANTA CATARINA, 1892, p. 219).

Sobre a Escola Normal, o decreto reconhece suas precárias condições, mas a considera como um avanço para a formação de professores primários. O caminho escolhido é a articulação da Escola Normal ao ensino secundário:

A Escola Normal fica ainda longe do que deve ser por nos faltar prédios apropriados, pessoal técnico habilitado, mas já é um avanço para quem não tinha nenhum meio de preparar o professorado primário.

Consultando quanto possível os recursos financeiros e fundando-me nas bases do projeto n. 35 aprovado em $1^{\circ}$ discussão pelo $1^{\circ}$ Congresso Estadual estabeleci a Escola Normal, de modo a aproveitar os professores do Ginásio, sem deixar um sob a dependência do outro. O Ginásio com o regulamento que lhe é dado fica completamente habilitado a dar um ensino sólido e profícuo (SANTA CATARINA, 1892, p. 219-220).

A reforma da instrução pública do Estado, de 1892, vincula, mais uma vez, o Curso Normal ao Ensino Secundário, conforme indica a Lei $\mathrm{n}^{\circ} 155$, de $1^{\circ}$ de julho de 1892 :

Art. $5^{0}$ - O ensino secundário será organizado de conformidade com o programa do Ginásio nacional, e distribuído por estabelecimentos especiais fundados na Capital e Cidades principais do Estado, de modo seguinte:

Na Capital haverá um Colégio denominado "Ginásio Catarinense" tendo uma escola Normal, destinada ao preparo do professorado público.

Art. $6^{0}-\mathrm{O}$ atual Instituto Literário e Normal fundir-se-á no Ginásio Catarinense passando os lentes daquele a ocuparem as cadeiras idênticas deste e da Escola Normal, anexa, garantidos os direitos adquiridos. (SANTA CATARINA, 1892 apud SCHAFFRATH, 1999, p. 82). 
Desse modo, na década de 1890, acontece a primeira reorganização da Escola Normal, agora sob a égide da República ${ }^{9}$. Para Schaffrath (1999), essa organização forneceu a base sobre a qual se consolidou a Escola Normal em Santa Catarina: escola destinada à formação de quadros ao ensino primário e à formação cultural e intelectual da elite catarinense. A Escola Normal era uma reivindicação da elite e se constituía em um espaço de normatização de condutas, tanto para seus alunos quanto para aqueles que seriam educados por eles, ou seja, o povo a quem se pretendia civilizar.

Nesse contexto, a formação feminina é um aspecto destacado pela autora:

Enfim, destinado ao ornamento ou à profissão, o curso oferecido pela Escola Normal de 1892 estruturado pelo Estado Republicano, foi de grande importância para o ensino em Santa Catarina. Apropriada pela elite, que ou ilustrava-se às expensas dos cofres públicos, ou trabalhava na composição de um sistema de ensino que perpetuasse desigualdades sociais, a Escola Normal não se constituiu em uma via de mão única. Se ela ornamentava dotes culturais das moças das elites, ela também cumpria o papel de escola preparatória de docentes para o ensino primário que também era alvo do Estado Republicano (SCHAFFRATH, 1999, p. 128).

Entre os anos de 1892 e 1907, na Escola Normal concluíram o curso 49 alunas e seis alunos; destes, apenas 21 exerceram o magistério público em Santa Catarina. Desse contingente, uma parcela foi para as escolas ou aulas particulares, atuando como preceptores de crianças de famílias abastadas, e outros não trabalharam na profissão, buscando na formação apenas o aperfeiçoamento pessoal (SCHAFFRATH, 1999).

Com o início do novo século, o estado catarinense teve novamente modificações em sua estrutura educacional: primeiro, com a supressão do Ginásio Catarinense, em 1905, sendo que seus professores ficaram a serviço da Escola Normal; depois, com a fundação, em Florianópolis, do Ginásio Santa Catarina ${ }^{10}$, subsidiado pelo estado e dirigido por uma congregação religiosa. Essa modificação foi apoiada pelos pais, segundo expressa o então Governador do estado, Gustavo Richard (1907, p. 18): "O número crescente de matrículas naquele Instituto mostra a atração que sobre os pais de família exercem sua disciplina e método de ensino e faz prever o futuro que lhe é reservado".

Na mesma mensagem, Gustavo Richard (1907, p. 18) delineou o cenário em que se encontrava a Escola Normal e
9 Com relação ao Ensino Secundário, ao qual esteve tradicionalmente vinculado ao Curso Normal, Schaffrath (1999) indica que, em 1895, a capital contava com três escolas para o ensino secundário: a Escola Normal Catarinense, o Ginásio Catarinense e a Escola de Artes e Ofícios. No ano de 1897, foi expedido mais um regulamento da Escola Normal que apresentava como novidade a criação de duas escolas públicas de instrução primária, denominadas Escola Modelo, uma para meninos, regida por um professor, e outra para meninas, regida por uma professora.

10 No final de 1905, o governo do estado de Santa Catarina suprimiu o único colégio público e gratuito de ensino secundário existente no território catarinense e apoiou o estabelecimento do Ginásio Catarinense, dirigido pela Companhia de Jesus. A fundação do novo colégio provocou intenso debate público, especialmente, na imprensa escrita, que envolvia o seu caráter privado, a laicidade do ensino público, a subvenção pelo erário público estadual e a nacionalidade dos futuros dirigentes e professores, os padres jesuítas alemães. Apesar da querela escolar, o colégio dos jesuítas, localizado em Florianópolis, começou a funcionar regularmente em 15 de março de 1906, tornando-se, até a década de 1930, o único instituto de ensino secundário em Santa Catarina (DALLABRIDA, 2002). 
seus egressos, e expressou sua preocupação com o número reduzido de rapazes que frequentavam o curso para formação de professores:

A matrícula para o ano vigente é de 49 alunos, aumentada de 6 do ano anterior. Até a presente data concluíram o respectivo curso, recebendo diploma de normalista 49 alunas e 6 alunos. Este quadro mostra um fato notório, digno de reparo, a ausência quase completa de moços nos cursos daquele estabelecimento de instrução. (RICHARD, 1907, p. 18).

Tendo em vista a falta de professores para o ensino público, o Governador sugeriu que se permitisse aos candidatos normalistas que residissem fora da capital que prestassem um exame livre, anual, a ser realizado na Escola Normal, tendo por base seu programa de ensino. Caso aprovados, os docentes estariam habilitados a reger escolas de ensino primário para o sexo masculino (RICHARD, 1907).

Além da questão do necessário aumento do número de professores para as escolas primárias, o Governador propôs uma reforma geral do Ensino Normal em que as matérias seriam revistas, dando-lhe mais praticidade, diminuindo o tempo de formação. Contudo, houve um aumento na dificuldade de entrada: "Tenho o firme propósito de reformar esse ensino, simplificando as matérias de seu curso, reduzindo a três anos, exigindo provas mais completas no exame de admissão e tornando o programa mais prático" (RICHARD, 1907, p. 19).

Na esteira do que já expressava em sua mensagem sobre as mudanças do ensino Normal, Gustavo Richard, pelo Decreto $\mathrm{n}^{\circ} 348$, de 7 de dezembro de 1907 , reformou o Regulamento da Instrução Pública. O Governador considerava importante melhorar todo o ensino catarinense e previa isso a partir dos exames da Escola Normal e do aumento da fiscalização do ensino, entre outras medidas:

Que o Regulamento da Instrução Pública, atualmente em vigor, carece de uma reforma, de modo a melhorar as condições gerais de ensino tanto primário como secundário normal, adaptando-o aos melhores moldes da pedagogia moderna, já tornando efetivamente obrigatório o ensino primário, de acordo com o recenseamento escolar e uma realidade a fiscalização do ensino por meio de inspetores escolares, remunerados, já Grupos Escolares e Jardins de Infância e tornando mais acessíveis a todas as vantagens que resultarem dos Exames da Escola Normal. (RICHARD, 1907, p. 98). 
Cabe destacar que, em 1907, Gustavo Richard, a fim de modernizar a Educação catarinense, com base no modelo paulista, inaugurado com a reforma Caetano de Campos, de 1891, contratou o professor paulista Orestes de Oliveira Guimarães e sua esposa Cacilda Guimarães, a fim de organizarem o Colégio Municipal de Joinville.

A remodelação da educação paulista, operada por Caetano de Campos, tinha a Escola Normal de São Paulo como início da reforma geral da instrução pública. Embasada nos moldes científicos da época, a legislação paulista configurou o curso Normal com duração de três anos, com uma seção masculina e outra feminina, e 10 cadeiras. Para servir como espaço de prática de ensino para os alunos do terceiro ano do Curso Normal, fundou-se a Escola Modelo do Carmo. Segundo o próprio Caetano de Campos (1890a, p. 2 apud MONARCHA, 1999, p. 179), a "[...] chave de toda evolução do ensino escolar, como concebe o Decreto de 12 de Março, repousa sobre a prática que devem ter os alunos-mestres na escola modelo, mais do que sobre a ampliação do curso superior, com a criação de novas cadeiras".Desse modo, a nova estrutura curricular se baseava no aprender fazendo, privilegiando as atividades utilitárias.

De formação médica, Caetano de Campos se utiliza dos conceitos da biologia para compreender as ciências sociais, vendo "[...] o mundo orgânico, social e mental como fruto da evolução inscrita na realidade" (MONARCHA, 1999, p. 175). O método intuitivo, baseado nas formulações de Pestallozzi e Calkins, assumiu um papel central na formação dos professores no momento em que a observação, a experiência sensorial e a educação dos sentidos são didáticas consideradas compatíveis com a evolução natural do pensamento da criança.

Assim, como indicava a reforma de Caetano Campos em terras paulistas, o curso da Escola Normal em Santa Catarina, em 1908, assistiu à nova modificação pela incorporação de uma escola modelo, anexa às duas escolas da capital (feminina e masculina) para a prática dos futuros professores. Nesse mesmo momento, há a prescrição de que deveria ser criada uma classe infantil com base nas ideias de Froebel. Quanto às expectativas do curso da Escola Normal, Gustavo Richard (1908, p. 1) foi enfático: "Nutro a esperança que este Instituto de ensino, sob administração do seu proveito diretor, auxiliado pelo ilustrado corpo docente, de o resultado compensadores dos sacrifícios que faz o Estado".

Em nova mensagem do Governador, em 1909, ficou evidente o incremento do número de alunos da Escola Normal naquele ano, movimento que vinha se consolidando desde 1907: 
A matrícula neste estabelecimento foi em 1908 de 64 alunos, sendo: 10 do sexo masculino e 54 do sexo feminino, tendo concluído o curso 10 alunos. No corrente ano a matrícula chegou a 85 alunos, do sexo masculino $18 \mathrm{e}$ do feminino 67.

Comparado a matrícula de um ano para outro, vê-se diferença para mais de 21, prova evidente do desenvolvimento que vai tendo este estabelecimento, destinado ao preparo do professorado primário. (RICHARD, 1909, p. 14).

Em 1910, último ano da administração de Gustavo Richard, o número de alunos da Escola Normal continuou a crescer, alcançando mais de uma centena (105). Nas palavras do Governador: "Comparando a matrícula de um ano para outro, vê-se uma diferença para mais de 20 alunos, o que evidencia a prosperidade crescente deste instituto" (RICHARD, 1910, p. 18).

Além do ensino ministrado na Escola Normal, o Governador salientou, em uma de suas mensagens, o papel central da escola para civilizar o povo: "A escola deve ser organizada de conformidade com os métodos racionais, adotados nos países mais cultos, e é será o principal fator da civilização de um povo, devendo por esse motivo merecer cuidados especiais e o maior empenho dos poderes públicos" (RICHARD, 1908, p. 14).

Gustavo Richard (1908, p. 14) acreditava que uma das principais dificuldades a serem vencidas na formação do homem para o novo século seria o descuido dos pais com a educação dos filhos:

Um dos principais obstáculos que temos a vencer para colocar nosso ensino a altura que deve ocupar entre nós é a negligência com que os pais cuidam do futuro de seus filhos. Levado por uma indiferença inqualificável descuidam da instrução destes, lançando número crescido de crianças na mais completa ignorância, incompatível com as exigências do século (RICHARD, 1908, p. 14).

Pelas mensagens de Gustavo Richard, podemos notar o aumento significativo de alunos na Escola Normal entre os anos de 1907 e 1910, consolidando-se como um espaço para a formação dos professores primários. Além disso, o Governador deixa evidente o papel da escola: civilizar o povo, preparando-o para o novo século. Ao mesmo tempo, o discurso de culpabilização dos pais frente ao descaso da educação dos filhos também ecoa, ou seja, o governo repetia o discurso de décadas anteriores em que se isentava das responsabilidades de oferecer um melhor ensino para 
que mais catarinenses pudessem acessar a escola, e colocava, mais uma vez, a família como obstáculo para a concretização da instrução do povo catarinense. Desse modo, reafirmam-se, como indica Neckel (2003), as ideias moralizadoras que desqualificavam o povo e exigiam do Estado ações efetivas para sua conformação aos moldes do novo ideário republicano.

Em Santa Catarina, os impactos do regime republicano se fizeram sentir ainda no reordenamento das disputas e forças políticas das elites catarinenses no sentido da definição do controle do estado e dos cargos político-administrativos, os quais passaram a representar, não apenas influência política, assim como a manutenção das rendas familiares. Igualmente, manifestaram-se nos discursos a difusão de novos comportamentos e costumes para os habitantes dos espaços urbanos, em especial, para a capital, cidade que foi palco das disputas políticas e um lugar privilegiado para se observar a formulação dessas alocuções e seus impactos sobre os diferentes sujeitos sociais.

Ao analisar os processos sociais presentes nos primeiros anos da República em Santa Catarina, Neckel (2003) destaca as mudanças no espaço urbano da capital, permitindo compreender como tais discursos implicaram em um novo ordenamento na vida dos cidadãos. Dentre essas mudanças, é possível citar o embelezamento e a modernização das ruas, mesmo que isso significasse a mudança das famílias empobrecidas para espaços cada vez mais distantes do centro da cidade, bem como a mudança de hábitos e antigos costumes.

As reformas realizadas na área central da capital nessa época foram significativas: em 1909, foram instaladas as primeiras redes de água encanada; entre 1913 e 1917, foi construída a rede de esgotos; em 1910, foi instalada a iluminação pública com energia elétrica; em 1919, iniciou-se a construção da primeira avenida da cidade; de 1922 a 1926, foi construída uma ponte para ligar a Ilha de Santa Catarina ao continente fronteiriço (NECKEL, 2003). Todas essas mudanças dependeram da força de sua elite política, que não cedeu às pressões para mudar a capital para o interior e carreou recursos para a remodelação da cidade.

Em sua pesquisa, Neckel (2003) aponta a oposição que se gerou, no discurso da imprensa e dos administradores, entre a "antiga vila" e a "cidade moderna" que deveria ser construída, sendo um dos pontos centrais a solução dos problemas de higiene pública:

Para o poder público e setores mais abastados, tornou-se essencial dar um aspecto "agradável e sadio" a Florianópolis. A discussão do urbano e dos modos de vida de seus habitantes pode ser surpreendida como uma 
linguagem que, manifesta em novas edificações e traçados urbanos, procurou relacionar o ideário republicano com forças progressistas e modernizadoras, no momento em que seus portadores consolidavam-se no poder governamental. As insistências dos administradores em transformar Florianópolis em uma cidade "moderna e civilizada" sugerem que a "antiga vila" era incompatível com a nova ordem política que se instaurava. (NECKEL, 2003, p. 54).

A pressão para a aquisição dos novos comportamentos e costumes se fez sentir sobre as camadas empobrecidas por meio de políticas de saneamento e educação, bem como na forma de desqualificação de seus hábitos e defesa de outros valores sociais, especialmente, com relação ao trabalho e às formas de sobrevivência, conforme indica a autora:

Os hábitos de sobrevivência através de trabalhos informais, no centro da cidade e no interior da ilha, através das atividades pesqueiras e de lavouras sazonais, garantiam formas de subsistência próprias, permitindo que muitos vivessem conforme seus valores, necessidades físicas e socioculturais. Estas parcelas da população, diante dos valores e concepções reformistas foram desqualificadas; as imagens de estagnação para designar a situação de desencontro predominante em Florianópolis diante destes interesses em expansão foram construídas em simetria àquelas que passaram a definir estes habitantes como ociosos e não afeitos ao trabalho. (NECKEL, 2003, p. 63).

No que se refere às camadas médias e as famílias abastadas, a pressão se dava no sentido de aspirar distinções diante do restante da população, seja advogando o domínio de certas parcelas do espaço urbano, seja pela adoção de hábitos e sensibilidade demonstrativos de diferenciação social. Neckel (2003, p. 25) chama a atenção para a disputa que se estabelecia entre esses grupos concorrentes:

Envolvidos num movimento de auto-afirmação [sic], tais grupos passam a empenhar-se em parecer civilizados. Ansiosos por sua afirmação social, incorporavam as modas e hábitos que importavam do Rio de Janeiro. Na busca de influências, cargos e vantagens, a desqualificação do concorrente também era feita pela adoção de costumes modernos.

Dessa forma, as novas expectativas que se colocavam sobre os cidadãos podem ser assim sintetizadas: 
Ser moderno para ser do tempo da República era ter comportamentos compatíveis com a civilização: novos preceitos de higiene, uma nova moral, uma nova disciplina corporal, novos hábitos de morar e de usar o espaço público. A intervenção na paisagem urbana devia promover o progresso, a modificação dos habitantes, mesmo à custa da perda de experiências passadas, dos laços de antigas sociabilidades, dos lugares centrais da cidade (SERPA; RAMOS, 2003 apud NECKEL, 2003, n.p.).

Do ponto de vista das iniciativas referentes à instrução pública, os documentos aqui citados indicam que “[...] nos primeiros tempos do período republicano, o panorama geral da instrução pública catarinense apresentava-se desolador, o que era reconhecido abertamente pelo Governo" (FIORI, 1991, p. 77). A precariedade se fazia presente na infraestrutura das escolas, na sua distribuição pelo Estado e na formação dos professores.

No entanto, vimos que as ideias veiculadas pelas elites catarinenses atribuíam à população e aos seus modos de vida a causa do atraso, considerados não compatíveis com os ideais de civilização e progresso. Foram sobre a mudança de hábitos da população e, sobretudo, sobre a formação de uma nova mentalidade dos professores que se centraram as estratégias para a difusão das questões morais e de conformação que os dirigentes consideravam necessárias à República. Compreender esse processo histórico permite identificar a função social exercida pelos professores como funcionários do Estado desde o início de sua profissão, conforme ressalta Florestan Fernandes (1987, p. 16):

O próprio professor interessava à medida que era um agente puro e simples de transmissão cultural. [...] Nesse contexto, o intelectual era, por assim, dizer, domesticado, quer fosse de origem nobre ou de origem plebeia, automaticamente se qualificava como um componente da elite e, quando isso não ocorria, como sucedeu com os professores de primeiras letras, ele era um elemento de mediação, na cadeia interminável de dominação política e cultural.

\section{Referências}

BASTOS, Maria Helena Camara. Método intuitivo e lições de coisas por Ferdinand Buisson. História da Educação, v. 17, p. 231-253, 2013. 
BOTO, Carlota. Desencantamento da criança: entre a Renascença e o Século das Luzes. In: FREITAS, Marcos Cesar de; KUHLMANN JÚNIOR, Moises (org.). Os intelectuais na história da infância. São Paulo: Cortez, 2002. p. 11-6o.

CAMBI, Franco. História da Pedagogia. São Paulo: Editora da UNESP, 1999.

CAMPOS, Carmem Lucia. Santa Catarina, 1930: da degenerescência à regeneração. Florianópolis, SC: Editora da UFSC, 2008.

FERNANDES, Florestan. A formação política e o trabalho do professor. In: CATANI, Denice Bárbara et al. (org.). Universidade, escola e formação de professores. 2. ed. São Paulo: Brasiliense, 1987. p. 13-37.

FIORI, Neide Almeida. Aspectos da evolução do ensino público: ensino público e política de assimilação cultural em Santa Catarina nos períodos imperial e republicano. 2. ed. Florianópolis: Editora da UFSC, 1991.

LUCIANO, Fábia Liliã. Gênese e expansão do magistério público na Província de Santa Catharina nos anos de 1836-1889. 2001. $228 \mathrm{f}$. Tese (Doutorado em Educação). Universidade Estadual de Campinas, Campinas, 2001.

MELLO FILHO, João Capistrano Bandeira de. Fala com que abriu a $1^{\text {a }}$ sessão da $21^{\text {a }}$ legislatura da Assembleia Legislativa. Cidade do Desterro, 1876.

MONARCHA, Carlos. Escola Normal da Praça: o lado noturno das luzes. Campinas, SP: Editora da UNICAMP, 1999.

NECKEL, Roselane. A República em Santa Catarina: modernidade exclusão. Florianópolis, SC: Editora da UFSC, 2003.

PAIVA, Vanilda. História da educação popular no Brasil: educação popular e educação de adultos. 6. ed. São Paulo: Loyola, 2003.

PROVÍNCIA DE SANTA CATARINA. Lei no $\mathbf{8 0 7}$, de 20 de abril de 1876. Cria uma escola normal, que funcionará no edifício do Ateneu Provincial. Desterro, 1876, p.81-82.

PROVÍNCIA DE SANTA CATARINA. Lei no $\mathbf{8 9 8}$, de 1 de abril de 1880. Autoriza o presidente da província a reorganizar a instrução publica. Desterro, 1880, p.62-65. 
PROVÍNCIA DE SANTA CATARINA. Em execução à Lei n 1029 , de 29 de maio de 1883, o presidente da província Theodoro Carlos de Farias Souto expediu o seguinte regulamento. Palácio da Presidência, Desterro, 14 ago. 1883, p.749-763.

RICHARD, Gustavo. Mensagem lida na sessão de abertura do Congresso Representativo. Florianópolis, 1907.

RICHARD, Gustavo. Mensagem lida na sessão de abertura do Congresso Representativo. Florianópolis, 1908.

RICHARD, Gustavo. Mensagem lida na sessão de abertura do Congresso Representativo. Florianópolis, 1910.

SANTA CATARINA.. Decreto no $\mathbf{1 5 5}, 10$ de junho de 1892. Reforma a Instrução Pública do Estado. Desterro: Gabinete da Typographia D O Dia, 1892.

SANTA CATARINA. Decreto no $\mathbf{3 4 8}, 7$ de dezembro de 1907. Reformando o regulamento da instrução publica. Desterro, 1907, p .98-99.

SCHAFFRATH, Marlete dos Anjos Silva. A Escola Normal Catharinense de 1892: profissão e ornamento. 1999. 146f. Dissertação de Mestrado - Universidade Federal de Santa Catarina, Florianópolis, 1999.

SCHAFFRATH, Marlete dos Anjos Silva. Escola Normal: o projeto das elites brasileiras para a formação de professores e professoras. In: ENCONTRO INTERDISCIPLINAR DE PESQUISA EM ARTES, 1., 2008, Curitiba. Anais. Curitiba: Unespar, 2008. p. 142-152.

WEISS, Jussemar. Guizot e a Educação. História da Educação, v. 5, n.10, p. 43-53, 2001.

Enviado em: 16-07-2018

Aceito em: 10-06-2020 Publicado em: 05-08-2020 